\title{
ALCOHOL CONSUMPTION AND THE RISK OF BREAST CANCER: A REPORT FROM THE TECUMSEH COMMUNITY HEALTH STUDY
}

\author{
Michael S. Simon,* Wendy Carman, Robert Wolfe and \\ DAVID SCHOTTENFELD
}

\begin{abstract}
Departments of Epidemiology and Biostatistics, School of Public Health, University of Michigan, Ann Arbor, Michigan, U.S.A.
\end{abstract}

(Received in revised form 1 January 1991)

\begin{abstract}
The relationship between prior alcohol consumption and the risk of breast cancer was studied in 1954 women in the Tecumseh Community Health Study (TCHS) who entered the cohort in 1959-1960 and were followed potentially for 28 years. The mean alcohol consumption at baseline was 0.89 (SD 2.2) oz/week for premenopausal women and 0.85 (SD 2.2) oz/week for postmenopausal women. Only $25 \%$ of the cohort consumed more than $0.5 \mathrm{oz}$ of ethanol/week or about $1.6 \mathrm{~g} /$ day. The adjusted relative risks (RRs) for breast cancer associated with the use of ethanol vs never drinking were $0.93(95 \% \mathrm{CI}, 0.40-2.18)$ for ex-drinkers, $1.08(95 \% \mathrm{CI}, 0.64-1.82)$ for $0-<1 \mathrm{drink} / \mathrm{day}$, $1.23(95 \% \mathrm{CI}, 0.49-3.10)$ for $1-<2$ drinks/day and $1.12(95 \% \mathrm{CI}, 0.25-5.01)$ for $\geqslant 2$ drinks/day. There were only 37 subjects in the group at the highest level of consumption ( $\geqslant 2$ drinks/day). There was no significant interaction between alcohol and the period of onset of breast cancer (premenopausal or postmenopausal). In the TCHS, alcohol consumption generally at levels not exceeding 2 drinks/day, was not significantly associated with an increased risk of breast cancer. Although we have found little excess risk associated with alochol consumption, the wide confidence intervals summarized above are not inconsistent with previously published reports that have suggested a modest positive association.
\end{abstract}

Breast cancer Alcohol consumption Epidemiology Tecumseh

\section{INTRODUCTION}

In the past 13 years, there have been at least 15 case-control and 6 cohort studies concerning the relationship between prior alcohol consumption and the subsequent development of breast cancer. While 7 case-control and 1 cohort study have not shown an association [1-8], other reports, namely 9 case-control and 5 cohort studies, have suggested a relationship with relative risks (RRs) in the range of $1.5-2.0$

*Address all correspondence to: Michael S. Simon, Assistant Professor of Medicine, Division of Hematology and Oncology, Wayne State University School of Medicine, P.O. Box 02188, Detroit, MI 48202-0188, U.S.A.
[9-22]. Of potential biologic interest has been the observation in 3 studies that the greatest excess risk may be associated with the onset and interval of exposure at younger ages $[13,15,17]$, or potentiated in women of lean body mass $[20,21]$. While the RRs in women at risk have been generally $<2.0$, the levels of drinking have been about 1 drink/day (10-15 $\mathrm{g}$ of ethanol) or less and would apply to a large segment of the population [23]. The issue of whether alcohol is truly a risk factor for breast cancer is of particular importance given the increasing incidence rates of breast cancer since 1973, particularly in women over 50 years of age [24], the estimated proportion of the population exposed, and the 
relative inability of established risk factors to predict occurrences in more than one-third of the population at risk.

We conducted a study using the Tecumseh cohort to determine whether prior alcohol consumption is a risk factor in the natural history of breast cancer. We also sought to determine whether alcohol consumption at baseline or past alcohol intake is associated with the risk of breast cancer limited to a specific period of onset, i.e. premenopausal or postmenopausal.

\section{METHODS}

\section{The Tecumseh community cohort}

The Tecumseh Community Health Study (TCHS) is an ongoing longitudinal health project conducted by the University of Michigan School of Public Health in a small town in southeastern Michigan $[25,26]$. Interviews and medical examinations were conducted in 3 major cycles, the first of which was conducted in 1959-1960. Mortality ascertainment has been completed successfully on more than $99 \%$ of the previously examined subjects. Subjects who enrolled in the first examination cycle comprised the cohort at risk of breast cancer.

\section{Measurement of variables}

Trained interviewers collected information on alcohol consumption. Subjects were asked how many $8 \mathrm{oz}$ glasses and/or $12 \mathrm{oz}$ cans and/or bottles of beer, $3 \mathrm{oz}$ glasses of table and/or fortified wine and $1.5 \mathrm{oz}$ shots of hard liquor they had consumed per week, month or year. If greater amounts of alcohol were consumed over a specific time period, the frequency and amount were determined for that time and prorated over the entire year. Total consumption, measured in oz/week, was constructed assuming standard equivalents per unit of each specific beverage. Ethanol content was assumed to be $4 \%$ for beer, $15 \%$ for wine and $45 \%$ for other liquors [27].

Current ethanol intake is reported as oz of ethanol consumed/week and is estimated using the baseline (1959-1960) reports of frequency of drinking and usual amounts consumed. Noncurrent drinkers are coded as consuming $0 \mathrm{oz}$ of ethanol/week. Past history of ethanol use is also measured as oz of ethanol consumed/week. The amount ever consumed equals the current amount for current drinkers and equals the amount previously consumed, if any, for current non-drinkers. $1 \mathrm{oz}$ of ethanol is equal to $23 \mathrm{~g}$ of ethanol which is equivalent to 2 average drinks.

Most of the covariates were measured only at baseline, although several were repeated at various intervals to obtain either an average value or to verify the accuracy of the baseline measurement. Discrepancies between successive data collections were resolved by using the information collected nearest in time after the occurrence of the reported event. Reproductive history obtained at the time of entry into the cohort included the number of prior live and non-live births and the number of prior pregnancies; subsequent reproductive events were documented after the time of entry. Life table analysis was used to estimate age of menopause for the $2.8 \%$ of the women whose age of menopause was not reported. Other variables included history of nulliparity, mother's age at first birth, age at menarche, family history of breast cancer in a mother or sister, smoking history, body mass (BMI) computed as the Quetelet Index or weight (kg) divided by height ${ }^{2}$ $\left(\mathrm{m}^{2}\right)$, subscapular and triceps skinfolds and the ratio of subscapular and triceps skinfold measurements.

\section{Population for analysis}

The target population for this analysis included all women in the Tecumseh population 21 years of age or older who responded in the first data collection and provided information regarding alcohol consumption. These 2420 women, or their next-of-kin if they were deceased, were mailed questionnaires to obtain information regarding their history of cancer. Responses were received for 2299 women detailing cancer history and the type of cancer, dates and places of diagnoses, and treatment for those with a positive history of any type of cancer. Death certificates were reviewed to augment this information. Permission was obtained to review the medical records of all subjects with reported cancer. Extensive efforts were made to provide pathological confirmation along with dates of diagnosis for all subjects with a history of any cancer other than skin cancer. Excluded from the final analyses were 34 subjects whose cancers could not be confirmed, 37 subjects who had verified cancer prior to entry or within 1 year of entry to the Tecumseh study, and 209 women with verified cancers which occurred following entry, but who did not have breast cancer. In addition, 65 women including 3 with verified breast cancer, were excluded because of missing covariate data. 
The remaining cohort consisted of 1954 women, 87 of whom developed breast cancer during the 28 years of follow-up. For the analysis by menopausal status, 1340 women contributed follow-up time prior to menopause, and 1706 women after menopause. Breast cancer was detected in 20 women during the time of their premenopausal follow-up, and in 64 women during their postmenopausal follow-up. Three cases were not classified by menopausal status.

\section{Study design}

We utilized a cohort design to examine potential risk factors for breast cancer in the women in the Tecumseh population who were cancer-free at baseline [28]. Cox's proportional hazards regression models were used to estimate the association between characteristics of the subject measured at entry and subsequent breast cancer rates. Homogeneous age groups were defined by stratifying the cohort into the 5 - and 10-year age intervals identified in Table 1.

Initially, each putative risk factor was analyzed separately, with adjustment only for age. Subsequently, the multivariate regression model analyzed the simultaneous independent effects of alcohol intake on breast cancer incidence with that of other covariates such as age, education, family history of breast cancer, age at menarche, parity, age at first birth, BMI, subscapular and triceps skin folds and smoking history [29]. The results of these analyses were summarized in terms of risk ratios (RRs) and $95 \%$ confidence intervals.

\section{RESULTS}

Table 1 describes the age distribution and breast cancer incidence in the TCHS. There were 87 cases occurring in a cohort of 1954

Table 1. Age distribution and diagnosis of breast cancer in the TCHS

\begin{tabular}{cccc}
\hline $\begin{array}{c}\text { Age }(\mathrm{yr}) \\
\text { at entry } \\
\text { into cohort }\end{array}$ & $n$ & \multicolumn{1}{c}{$\%$} & Cases \\
\hline $21-24$ & 221 & $(11.3)$ & 3 \\
$25-29$ & 287 & $(14.7)$ & 11 \\
$30-34$ & 306 & $(15.6)$ & 8 \\
$35-39$ & 287 & $(14.7)$ & 18 \\
$40-49$ & 364 & $(18.6)$ & 18 \\
$50-59$ & 250 & $(12.8)$ & 19 \\
$60-69$ & 138 & $(7.1)$ & 6 \\
$70+$ & 101 & $(5.2)$ & 4 \\
Total & 1954 & $(100)$ & 87 \\
\hline
\end{tabular}

Tablc 2. Characteristics of the subjects

\begin{tabular}{|c|c|}
\hline \multicolumn{2}{|l|}{$(n=1954)$} \\
\hline Variable & $\%$ \\
\hline \multicolumn{2}{|l|}{ Education } \\
\hline High school graduate & 61.4 \\
\hline Some college & 21.6 \\
\hline $\begin{array}{l}\text { Positive family history } \\
\text { of breast cancer* }\end{array}$ & 8.2 \\
\hline \multirow[t]{2}{*}{ Nulliparous } & 12.2 \\
\hline & Mean (SD) \\
\hline Mother's age at first birth (yr) & $22.6(3.9)$ \\
\hline Age at menarche & $13.0(1.5)$ \\
\hline BMI $\left(\mathrm{kg} / \mathrm{m}^{2}\right)$ & $25.3(5.0)$ \\
\hline Smoking (No. cigarettes/day) & $5.0(8.5)$ \\
\hline Subscapular skinfold (cm) & $20.6(10.8)$ \\
\hline Triceps skinfold $(\mathrm{cm})$ & $22.8(7.9)$ \\
\hline Subscapular/triceps & $0.89(0.33)$ \\
\hline
\end{tabular}

women $(4.45 \%)$. Table 2 summarizes the distribution of baseline demographics and risk factor characteristics of the cohort. The mean age at the start of follow-up was 33 years among women with premenopausal follow-up, and 51.0 years among women with postmenopausal follow-up.

Table 3 shows the distribution of alochol consumption in relation to menopausal status. About $63 \%$ of the premenopausal and $57 \%$ of the postmenopausal women reported ethanol consumption at baseline (drinker at entry). Among the baseline users, the mean ethanol intake in oz/week was 0.893 (SD 2.2) for premenopasual women and 0.852 (SD 2.2) for postmenopausal women. When past alcohol consumption by ex-drinkers was considered in addition to the amount consumed at baseline (ever drinker) the mean intake per week was $1.00 \mathrm{oz}$ (SD 2.3) for premenopausal women and $0.983 \mathrm{oz}$ (SD 2.4) for postmenopausal women.

Table 3. Distribution of alcohol consumption and menopausal status

\begin{tabular}{lcc}
\hline & $\begin{array}{c}\text { Premenopausal } \\
(n=1340)\end{array}$ & $\begin{array}{c}\text { Postmenopausal } \\
(n=1706)\end{array}$ \\
\hline $\begin{array}{l}\text { \% Drinker at entry* } \\
\% \text { Ever drinker }\end{array}$ & 63.3 & 56.9 \\
\hline Alcohol level $\dagger$ & 77.6 & 66.6 \\
(oz/week) & Mean (SD) & Mean (SD) \\
\hline At entry & $0.893(2.2)$ & $0.852(2.2)$ \\
Ever & $1.00(2.3)$ & $0.983(2.4)$ \\
\hline
\end{tabular}

*Drinker at entry refers to subjects who only reported alcohol intake at baseline, while ever drinker includes those who drank at entry in addition to those who reported being ex-drinkers.

$\dagger 1$ oz of ethanol is equal to $23 \mathrm{~g}$ of ethanol which is roughly equivalent to 2 drinks. 
Only $25 \%$ of the women drank $>0.5$ oz of ethanol/week and $17.5 \%$ drank $>1$ oz/week.

An analysis of the relationship of alcohol consumption to potential confounding factors was performed. Higher levels of alcohol consumption were significantly associated with cigarette smoking, a lean body habitus, and the achievement of higher education.

The adjusted RRs of potential risk factors for breast cancer were determined from a Cox regression analysis of time to cancer (Table 4). Neither the number of live births, non-live births, nor the number of pregnancies, after adjustment for maternal age at first live birth and history of nulliparity were significantly related to breast cancer incidence and therefore, were not included in the analyses reported. Older maternal age at first live birth, history of nulliparity, younger age at menarche, older age at menopause and family history of breast cancer (in mother and/or sister) were all significant risk factors for breast cancer. There was no significant association of breast cancer incidence with level of education, BMI, subscapular/triceps skinfold or smoking history.

Table 5 shows the adjusted RRs for breast cancer and alcohol consumption as a categorical variable. There was no significant association

Table 4. Adjsuted RRs of potential risk factors for breast cancer*

\begin{tabular}{|c|c|c|}
\hline Risk factors & $\mathbf{R R}$ & $(95 \% \mathrm{CI})$ \\
\hline \multicolumn{3}{|l|}{ Education } \\
\hline $\begin{array}{l}\text { High school graduate } \\
\text { vs non-graduate }\end{array}$ & 1.04 & $(0.62-1.76)$ \\
\hline $\begin{array}{l}\text { More than high school } \\
\text { vs high school graduate }\end{array}$ & 0.87 & $(0.50-1.51)$ \\
\hline $\begin{array}{l}\text { FH of breast cancert } \\
\text { yes vs no }\end{array}$ & 2.24 & $(1.24-4.03) \ddagger$ \\
\hline $\begin{array}{l}\text { Nulliparous vs parous } \\
\text { at entry }\end{array}$ & 1.88 & $(1.07-3.31) \ddagger$ \\
\hline $\begin{array}{l}\text { Age at first live birth } \\
(\mathrm{yr}) \S \uparrow\end{array}$ & 1.09 & $(1.03-1.14) \ddagger$ \\
\hline $\begin{array}{l}\text { Age at menarche } \\
(\mathrm{yr}) \mathrm{T}\end{array}$ & 0.86 & $(0.74-0.99) \ddagger$ \\
\hline $\begin{array}{l}\text { Smoking (No. cigarettes/ } \\
\text { day) } \emptyset\end{array}$ & 1.01 & $(0.98-1.04)$ \\
\hline BMI $\left(\mathbf{k g} / \mathrm{m}^{2}\right) \top$ & 0.99 & $(0.95-1.05)$ \\
\hline $\begin{array}{l}\text { Subscapular/triceps } \\
\text { skinfold ratio }\end{array}$ & 0.82 & $(0.41-1.66)$ \\
\hline
\end{tabular}

* Risk factors were determined at baseline. RRs were derived from multivariate proportional hazards models including all of the potential risk factors and drinking status (never, past or current).

fIncludes family history of breast cancer in the mother and/or sister.

†Significant at the 0.05 level.

\$The age at first live birth for nulliparous women was coded as $22 \mathrm{yr}$, the average age at first live birth of the parous women.

TThe RR reported is that associated with the unit increase in these continuous measures.
Table 5. Adjusted RRs for breast cancer and alcohol consumption*

\begin{tabular}{lccc}
\hline Alcohol level & $n$ & RR & $95 \%$ CI \\
\hline Never & 657 & 1.00 & \\
Ex-drinkers & 199 & 0.93 & $(0.40-2.18)$ \\
$0-<1$ Drink/day & 924 & 1.08 & $(0.64-1.82)$ \\
$1-<2$ Drinks/day & 97 & 1.23 & $(0.49-3.10)$ \\
$\geqslant 2$ Drinks/day & 37 & 1.12 & $(0.25-5.01)$ \\
\hline
\end{tabular}

*RRs were derived from multivariate proportional hazards models including the covariate's age, BMI, subscapular and triceps skinfold measurements, education levels, cigarette use, family history of breast cancer, age at menarche, mother's age at first live birth, and parity.

between alcohol use as a categorical variable and breast cancer risk. The adjusted RRs for intake of $0-<1,1-<2$, or $>2$ drinks per day were not significant. However, the confidence intervals for the RRs were wide at high levels of alcohol consumption because of the small number of individuals in those categories.

Table 6 shows the adjusted RRs for breast cancer and alcohol consumption in terms of drinking practice and as a continuous variable. When the period of onset of breast cancer was analyzed for interaction, no significant association was seen. For premenopausal women, the estimated increase in RR (1.57) with alcohol use as a categorical variable was not statistically significant, and was not demonstrated when alcohol use was measured as a continuous variable. For postmenopausal women the estimated RRs and dose-response relationships were non-significant.

\section{DISCUSSION}

Alcohol consumption was not significantly associated with an increased risk of breast

Table 6. RRs for breast cancer and alcohol consumption by menopausal status adjusted for other potential risk factors*

\begin{tabular}{lll}
\hline Risk factor & $\begin{array}{c}\text { Premenopausal } \\
\text { RR (95\% CI) }\end{array}$ & $\begin{array}{c}\text { Postmenopausal } \\
\text { RR (95\% CI) }\end{array}$ \\
\hline $\begin{array}{l}\text { Ever drinker } \\
\text { yes vs no }\end{array}$ & $1.57(0.43-5.71)$ & $0.94(0.53-1.67)$ \\
$\begin{array}{c}\text { Current ethanol } \\
\text { consumption } \\
\text { (oz/week) }\end{array}$ & $0.93(0.90-1.25)$ & $1.04(0.96-1.14)$ \\
$\begin{array}{c}\text { Ethanol: current or } \\
\text { past consumption } \\
\text { (oz/week) }\end{array}$ & $0.88(0.63-1.23)$ & $1.04(0.95-1.13)$ \\
\hline
\end{tabular}

*RRs were derived from multivariate proportional hazards models including the covariate's age, BMI, subscapular and triceps skinfolds, education levels, cigarette use, family history of breast cancer, age at menarche, mother's age at first live birth and parity.

†Non-current drinkers including never and past drinkers are coded as $\mathbf{0}$ oz of ethanol/week.

\$Subjects who reported past drinking were identified in the analysis using a dummy variable. 
cancer in the TCHS cohort. The existence of an association between alcohol consumption and breast cancer risk would be of great significance and concern [30]. It has been proposed that alcohol may act as a co-carcinogen or promoter in breast carcinogenesis, mediating its putative effects through endocrine, immunologic or biochemical mechanisms [30-32]. Some casecontrol [9-17] dnd cohort studies [18-22] have suggested an increased risk while other casecontrol studies [1-7], and 1 recent study of the Framingham cohort [8], have not substantiated any association.

Table 7 highlights the results of 6 recent cohort studies. While Willett et al. [20] and Schatzkin et al. [21] showed a significant association between alcohol consumption and breast cancer at a consumption level of 5-15 g/day, no significant effects were seen in other cohort studies until alcohol intake reached $34.5 \mathrm{~g} /$ day in 1 study [18], and at least $69 \mathrm{~g} /$ day in 2 others $[19,22]$.

In the Framingham cohort [8] only 19 women drank as much as $15 \mathrm{~g}$ /day and no significant alcohol-breast cancer association was seen. In a recent case-control study in northern Italy [16], an increased risk was only noted at an exposure level of $40 \mathrm{~g} /$ day. No such association was recorded in the analysis from the Centers for Disease Control's Cancer and Steroid Hormone Study [6], with exposure as high as
$36 \mathrm{~g} /$ day. In addition, no association was seen in another recent case-control study for levels of alcohol intake up to at least $23 \mathrm{~g}$ /day [7]. In a meta-analysis of 12 case-control and 4 cohort studies, Longnecker et al. [33] inferred that there was a significant effect at an average consumption level of $24 \mathrm{~g} /$ day, or about 2 drinks/day. The results reported in relation to alcohol consumption in the Tecumseh cohort, with a mean of $0.90 \mathrm{oz} /$ week $(3.0 \mathrm{~g} / \mathrm{day})$, do not preclude a threshold effect at a higher level of exposure. In fact, only $25 \%$ of our cohort drank $>0.5 \mathrm{oz}$ of ethanol/week $(1.6 \mathrm{~g} /$ day $)$.

A limitation of the studies to date is that alcohol intake has been measured primarily at baseline and not as a cumulative exposure standardized for body weight. A cumulative measure of alcohol exposure could help determine whether the risk of alcohol consumption is limited to a specific period of onset of breast cancer. As with all studies of alcohol consumption based on self-reports, there is the potential for misclassification, in particular for underreporting. Such bias may be greater in a smaller mid-western community such as Tecumseh than in larger urban areas.

Since the risk factors for premenopausal and postmenopausal breast cancer may differ, we examined these two periods of follow-up separately. There was no consistent or significant

Table 7. A comparison of cohort studies of alcohol consumption and breast cancer risk

\begin{tabular}{|c|c|c|c|c|c|c|}
\hline \multirow{3}{*}{$\frac{\text { Author(s) }}{\text { Schatzkin et al. [8] }}$} & \multirow{3}{*}{$\frac{\text { Cases/Cohort }}{143 / 2636}$} & \multicolumn{3}{|c|}{ Alcohol exposure } & \multirow{2}{*}{\multicolumn{2}{|c|}{$\begin{array}{c}\text { Multivariate } \\
\text { adjusted } \\
\text { RR }(95 \% \mathrm{CI})^{*}\end{array}$}} \\
\hline & & \multirow{3}{*}{$\begin{array}{c}\text { drinks/day } \\
0.01-0.12 \\
0.13-0.43\end{array}$} & \multirow{2}{*}{$\frac{\mathrm{g} / \text { day }}{0.1-1.4}$} & \multirow{2}{*}{$\frac{\text { oz/day }}{0.005-0.06}$} & & \\
\hline & & & & & 1.0 & $(0.6-1.5)$ \\
\hline & & & $1.5-4.9$ & $0.07-0.22$ & 0.7 & $(0.4-1.1)$ \\
\hline & & $\geqslant 0.43$ & $\geqslant 5.0$ & $\geqslant 0.22$ & 0.6 & $(0.4-1.0)$ \\
\hline Hiatt and Bawol [18] & $694 / 88,477$ & $\begin{array}{l}\leqslant 2 \\
\geqslant 3\end{array}$ & $\begin{array}{l}\leqslant 23.0 \\
\geqslant 34.5\end{array}$ & $\begin{array}{l}\leqslant 1.0 \\
\geqslant 1.5\end{array}$ & $\begin{array}{l}0.98 \\
1.38\end{array}$ & $\begin{array}{l}\text { (NA) } \dagger \\
\text { (NA) }\end{array}$ \\
\hline \multirow[t]{4}{*}{ Hiatt et al. [19] } & $303 / 58,347$ & $<1$ & $<11.5$ & $<0.5$ & 1.21 & $(0.86-1.69)$ \\
\hline & & $1-2$ & $11.5-23$ & $0.5-1.0$ & 1.50 & $(0.98-2.29)$ \\
\hline & & $3-5$ & $34.5-57.5$ & $1.5-2.5$ & 1.47 & $(0.78-2.79)$ \\
\hline & & $\geqslant 6$ & $\geqslant 69$ & $\geqslant 3$ & 3.30 & $(1.18-9.28)$ \\
\hline \multirow[t]{4}{*}{ Willett et al. [20] } & $601 / 89,538$ & $\leqslant 0.13$ & $<1.5$ & $\leqslant 0.07$ & 1.0 & $(0.8-1.3)$ \\
\hline & & $0.13-0.43$ & $1.5-4.9$ & $0.07-0.22$ & 0.9 & $(0.7-1.2)$ \\
\hline & & $0.43-1.30$ & $5.0-14.9$ & $0.22-0.65$ & 1.3 & $(1.0-1.6)$ \\
\hline & & $>1.3$ & $>15.0$ & $>0.65$ & 1.6 & $(1.3-2.0)$ \\
\hline \multirow[t]{3}{*}{ Schatzkin et al. [21] } & $121 / 7188$ & $0-0.10$ & $0-1.2$ & $0-0.05$ & 1.4 & $(0.8-2.5)$ \\
\hline & & $0.11-0.43$ & $1.3-4.9$ & $0.055-0.22$ & 1.6 & $(0.9-3.1)$ \\
\hline & & $\geqslant 0.43$ & $\geqslant 5$ & $\geqslant 0.22$ & 2.0 & $(1.1-3.7)$ \\
\hline \multirow[t]{6}{*}{ Garfinkel et al. [22] } & $2334 / 581,321$ & 1 & 11.5 & 0.5 & 1.18 & $(1.03-1.36)$ \\
\hline & & 2 & 23.0 & 1.0 & 1.06 & $(0.86-1.30)$ \\
\hline & & 3 & 34.5 & 1.5 & 1.28 & $(0.95-1.74)$ \\
\hline & & 4 & 46.0 & 2.0 & 1.36 & $(0.90-2.07)$ \\
\hline & & 5 & 57.5 & 2.5 & 2.10 & $(1.18-3.72)$ \\
\hline & & $>6$ & 69.0 & 3.0 & 1.60 & $(1.00-2.56)$ \\
\hline
\end{tabular}

*The $R R$ is for each exposure level relative to no alcohol consumption.

$\uparrow N A-$ not available. 
relationship between alcohol consumption and the incidence of breast cancer in either premenopasual or postmenopausal women. In a recent case-control study in The Netherlands, the association with prior alcohol consumption was described in premenopausal breast cancer cases, suggesting that an alcohol effect may be interactive with a particular period of exposure [17].

In the Tecumseh cohort we found no alcoholbreast cancer association with baseline or with baseline and past alcohol consumption up to 2 drinks/day. Our study is consistent with the findings in the Framingham cohort [8], and the general conclusions of Longnecker et al. [33], although it cannot address the nature of the dose-response relationship at higher levels, as indicated in the literature, because of the low exposure levels reported in our study group. A positive relationship may be dose-dependent or consistent with a threshold response. Indeed, our results for exposure at $0-1$ and $1-2$ drinks/day, are not inconsistent with the available data reported elsewhere.

Acknowledgements-This research was supported by the American Cancer Society Contract pDT-286 (WACS). The authors thank Mary Ann Terranova for typing the manuscript.

\section{REFERENCES}

1. Byers T, Funch DP. Alcohol and breast cancer (Letter). Lancet 1982; 1: 799-800.

2. Paganini-Hill A, Ross RK. Breast cancer and alcohol consumption (Letter). Lancet 1983; 2: 626-627.

3. Begg CB, Walker AM, Wessen B, Zelen M. Alcohol consumption and breast cancer (Letter). Lancet 1983; 1: 293-294.

4. Webster LA, Layde PM, Wingo PA, Ory HW, The Cancer and Steroid Hormone Study Group. Lancet 1983; 2: 724-726.

5. Harris RE, Wynder EL. Breast cancer and alcohol consumption: a study in weak associations. JAMA 1988; 259: 2867-2871.

6. Chu SY, Lee NC, Wingo PA, Webster LA. Alcohol consumption and the risk of breast cancer. Am J Epidemiol 1989; 130: 867-877.

7. Rosenberg L, Palmer JR, Miller DR, Clauke EA, Shapiro $\mathrm{S}$. A case-control study of alcoholic beverage consumption and breast cancer. Am J Epidemiol 1990; 131: 6-14.

8. Schatzkin A, Carter CL, Green SB, Kreger BE, Splansky GL, Anderson KM, Helsel WE, Kannel WB. Is alcohol consumption related to breast cancer? Results from the Framingham heart study. J Natl Cancer Inst 1989; 81: 31-35.

9. Williams RR, Horm JW. Association of cancer sites with tobacco and alcohol consumption and socioeconomic status of patients: interview study from the third national cancer survey. J Natl Cancer Inst 1977; 58: 525-547.

10. Rosenberg L, Slone D, Shapiro S, Kaufman DW, Helmrich SP, Miettiner OS, Stolley PD, Levy M,
Rosenhein NB, Schottenfeld D, Engle RL. Breast cancer and alcoholic beverage consumption. Lancet 1982; 1: 267-271.

11. Le MG, Hill C, Kramar A. Alcoholic beverage consumption and breast cancer in a French case-control study. Am J Epidemiol 1984: 120: 355-377.

12. Le MG, Moulton LH, Hill C, Kramar A. Consumption of dairy produce and alcohol in a case-control study of breast cancer. J Natl Cancer Inst 1986; 77 : 633-636.

13. Harvey EB, Schairer C, Brinton LA, Hoover RN, Fraumeni JF. Alcohol consumption and breast cancer. J Natl Cancer Inst 1987; 78: 657-661.

14. La Vecchia CL, Decarli A, Franceschi S, Gentile A, Negri E, Parazzini F. Dietary factors and the risk of breast cancer. Nutr Cancer 1987; 10: 205-214.

15. O'Connell DL, Hulka BS, Chambless LE, Wilkinson WE, Deubner DC. Cigarette smoking, alcohol consumption, and breast cancer risk. J Natl Cancer Inst 1987; 78: 229-234.

16. Toniolo P, Riboli E, Protta F, Charvel M, Cappa APM. Breast cancer and alcohol consumption: a case-control study in northern Italy. Cancer Res 1989; 49: 5203-5206.

17. Van't Veer P, Kok FJ, Hermus RJJ, Sturmans F. Alcohol dose, frequency and age at first exposure in relation to the risk of breast cancer. Int $\mathbf{J}$ Epidemiol 1989; 18: 511-517.

18. Hiatt RA, Bawol RD. Alcoholic beverages consumption and breast cancer incidence. Am J Epidemiol 1984; 120: $676-683$

19. Hiatt RA, Klatsky A, Armstrong MA. Alcohol and breast cancer in a prepaid health plan. Cancer Res 1988; 48: 2284-2287.

20. Willett WG, Stampfer MJ, Colditz GA, Rosner BA, Hennekens CH, Speizer FE. Moderate alcohol consumption and the risk of breast cancer. $\mathbf{N}$ Engl J Med 1987; 316: 1174-1180.

21. Schatzkin A, Jones DY, Hoover RN. Alcoholic consumption and breast cancer in the epidemiologic follow-up study of the First National Health and Nutritional Exam Survey. N Engl J Med 1987; 316: 1169-1173.

22. Garfinkel L, Boffetta P, Stellman SD. Alcohol and breast cancer: a cohort study. Prev Med 1988; 17: 686-693.

23. Wynder EL. Tumor enhancers: underestimated factors in the epidemiology of lifestyle associated cancers. Environ Health Perspect 1983; 50: 15-21.

24. National Cancer Institute. 1989 Annual Cancer Statistics Review. NIH Publ. No. 89-2789. Bethesda, Md: National Cancer Institute; 1989.

25. Napier JA. Field methods and response rates in the Tecumseh community health study. Am J Public Health 1962; 52: 208-216.

26. Epstein FH, Ostrander LD, Johnson BC, Payne MW, Hayner NS, Keller JB, Francis T. Epidemiological studies of cardiovascular disease in a total community-Tecumseh, Michigan. Ann Intern Med 1965; 62: 1170-1187.

27. Schork MA, Ozgoren F, Harburg E. Methods describing drinking profiles for ethanol usage. Technical Report. Ann Arbor, Mich.: Department of Biostatistics, University of Michigan; 1984.

28. Breslow NE, Day NE. Statistical Methods in Cancer Research. Vol. II-The Design and Analysis of Cohort Studies. Lyon: Oxford University Press; 1987.

29. Cox DR, Oakes DO. Analysis of Survival Data. London: Chapman \& Hall; 1984.

30. Wynder EL. American Health Foundation Workshop on Alochol and Breast Cancer. Introductory remarks. Prev Med 1988; 17: 667-669. 
31. Schrauzer GN, MCGinness JE, Ishmael D, Bell $L$. Alcoholism and cancer. J Stud Alcohol 1979; 40: 240-246.

32. Williams RR. Hypothesis: Breast and thyroid cancer and malignant melanoma promoted by alcohol- induced pituitary secretion of prolactin, T.S.H. and M.S.H. Lancet 1976; 1: 996-999.

33. Longnecker MP, Berlin JA, Orza MJ, Chalmers TC. A meta-analysis of alcohol consumption in relation to risk of breast cancer. JAMA 1988; 260: 652-656. 